\title{
Evaluation of the Land Surface Temperature using Satellite Images in Kathmandu Valley
}

\author{
Anil Aryal a , Bijay Man Shakya ${ }^{b}$, Manisha Maharjan ${ }^{c}$, \\ Rocky Talchabhadel ${ }^{\mathrm{d}}$, Bhesh Raj Thapa ${ }^{\mathrm{e}}$ \\ a, b Interdisciplinary Centre for River Basin Environment, University of Yamanashi, Kofu, Yamanashi, Japan \\ c Department of Environmental Engineering, Kyoto University, Katsura, Kyoto, Japan \\ d Texas A\&M AgriLife Research, Texas A\&M University El Paso, Texas, USA \\ e Universal Engineering and Science College, Kathmandu, Nepal \\ Corresponding Email: a anilsagar651@gmail.com
}

\begin{abstract}
Urbanization leads the conversion of green area to built-up area which eventually leads to increase in surface temperature and creates the urban heat islands. Kathmandu Valley (KV), one of the growing mega cities in South Asia in-terms of population density and urbanization, requires the monitoring of urban morphology for the proper assessment. Use of satellite images makes the work more easier. The present study focuses on the evaluation of Land Surface Temperature (LST) as a preliminary work of monitoring urban and periurban areas of Kathmandu Valley. We used Landsat-8 satellite images as an input to evaluate LST over different administrative units for the study period 2013-2019. The results of research showed that Kathmandu, Bhaktapur and Lalitpur administrative units have higher average LST (ranging from 22.1 to $36.9^{\circ} \mathrm{C}$ in the month of March and June respectively) comparing to other administrative units. The average LST was found to be higher in the month of June. The temporal results of LST portrays 2015 as the hottest year during the study period. Also, spatial and temporal evaluation of LST in KV suggests to increase the more green space in the urban areas to minimize surface temperature. Finally, the authors of current research recommends using the concept of remote sensing (satellite image analysis) as an alternative tool for monitoring urban morphology.
\end{abstract}

\section{Keywords}

Heatmap, Kathmandu Valley, Landsat-8, Land Surface Temperature, Urban Heat Island

\section{Introduction}

The Land Surface Temperature (LST) is one of the key climatic variable that establish an interaction between land surface and atmosphere. With the rapid increase in urbanization, land cover has been replaced by impervious land surfaces such as concretes. Change in land cover can alter the thermal properties and surface radiation which eventually varies humidity of the urban area (Meng et al., 2018). The alteration of land surface further might induce various environmental issues such as desertification and creation of urban heat islands (UHI). Thus, it is necessary to understand how LST change has occur especially in urban areas (Yamamoto et al., 2018).

LST is the radiative skin temperature of the land derived from solar radiation. In as simple meaning, LST is the degree of hotnesss the surface of Earth is felt when touched (Donlon et al., 2012). Effective radiating temperature from the Earth's surface is used to evaluate the LST as surface of earth is responsible for controlling the heat and water exchange with the atmosphere (Yuan and Bauer, 2007). Satellite based LST estimation has wide range of applications ranging from climate change, water management, crop management, land cover changes etc. LST obtained from satellite imageries is often used to monitor the urban climate and understand the environmental state for human sustainability. The state of urban cities are governed by the extent of urbanization which causes to rise the air and surface temperature of urban areas compared to the surrounding rural areas, called UHIs. Thus, LST is often applied for zoning the UHI regions.

The impervious area increased from $2.3 \%$ (1996) to $6.7 \%$ (2006) to $23.9 \%$ (2017) at Kandy City, Sri 
Lanka as witnessed from Landsat images (Dissanayake et al., 2019). Ravanelli et al. (2018) found that urbanization has greater impact in LST magnitude at Phoenix MA. Temporal analysis of mean land surface temperature showed an increase in the surface temperature of Central Delhi between 2010 and 2017 from $27.95^{\circ} \mathrm{C}$ to $33.21^{\circ} \mathrm{C}$ (Kumari et al., 2018). Increase in LST has induced the phenomenon of UHI which is the result of vegetation clearance during urbanization. The surface temperature analysis showed that the minimum and maximum temperatures at Skopje, Macedonia were $15^{\circ} \mathrm{C}$ and $37^{\circ} \mathrm{C}$ for 2013 , and $24^{\circ} \mathrm{C}$ and $49^{\circ} \mathrm{C}$ for 2017 (Kaplan et al., 2018). The spatial variability of LST showed higher intensity of surface temperature $\left(31.12^{\circ} \mathrm{C}\right)$ in built-up area while comparatively lesser intensity $\left(24.27^{\circ} \mathrm{C}\right)$ at water bodies in the year 2016 at densely populated Colombo city in Sri Lanka (Fonseka et al., 2019). Yang and Wang (1989) quantified that vegetative areas are comparatively cooler than non-vegetative area. They further identified that after plantation, mean daily temperature of built-up area and streets reduce by $0.5 \mathrm{~K}$ and $0.9 \mathrm{~K}$ respectively. Further, Surface Urban Heat Island (SUHI) was found to be more prevalent for the month of May to October in Beijing (Liu et al., 2016). Results of the research further stressed that SUHI intensity was more pronounced during the months of July and August.

This paper aims to evaluate the state of surface temperature (average, minimum and maximum) at different administrative units that are impacted by increasing surface temperature within the Kathmandu Valley (KV). The economic activities of $\mathrm{KV}$ has attracted many of the residents from all over the nation there by increasing the population density and eventually the built-up areas. Increase in the built-up area is supposed to rise the surface temperature. Thus, it is essential to carry out research relating to surface temperature in the populated basin like KV especially during the dry periods (March-August) to understand the impact posed by UHIs and changing climate variable such as temperature, humidity. The impact analysis guides the planners and managers to think of a way in minimizing the adverse effect of rising air and surface temperatures. The paper has been distributed as follows: Section 2 gives insight about the study area. Section 3 discusses on the materials used and methodology adopted to evaluate LST in the study area. Section 4 explains about the result obtained from the current research and discuss on the past work relating to LST in urban cities nearby. Section 5 concludes that the urban area (central KV) has higher intensity of surface temperature compared to peri-urban areas.

\section{Study Area}

The study area Kathmandu Valley (KV) is shown in Figure 1. KV is one of the biggest city in Nepal, in-terms of population and economic development, comprising an area of approximately $664 \mathrm{~km}^{2} . \mathrm{KV}$ is a home to about 4 million population and is situated in Bagmati province. The rate of increase of population and urbanization is high in KV compared to other big cities in the country. The valley is bowl shaped enclosed by mountains (Shakya et al., 2019) and extended from $\mathrm{E} 85^{\circ} 11^{\prime}-85^{\circ} 30^{\prime}$ to $\mathrm{N} 27^{\circ} 32^{\prime}-$ $27^{\circ} 49^{\prime}$ comprising the major cities Kathmandu, Lalitpur and Bhaktapur (Thapa et al., 2017).

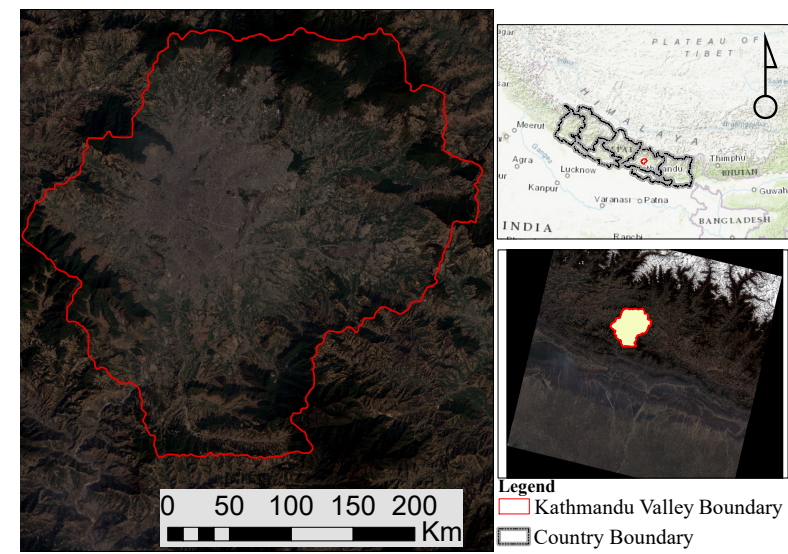

Figure 1: Kathmandu Valley study area as seen from Landsat-8 satellite image

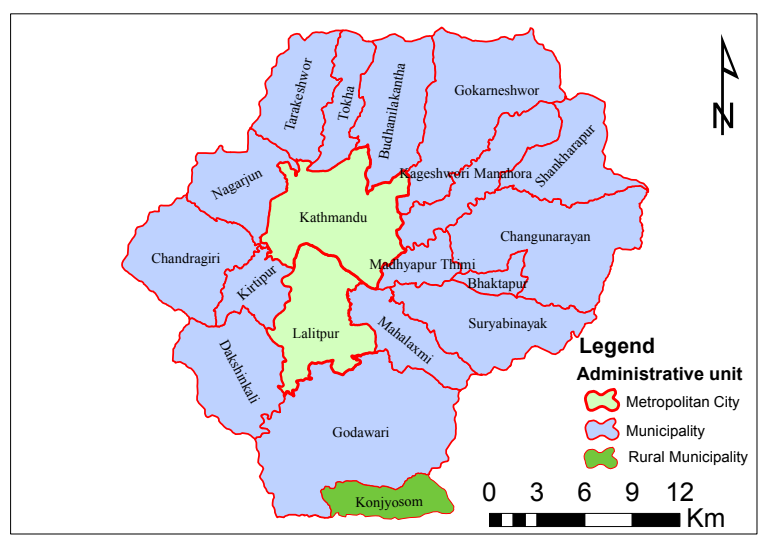

Figure 2: Kathmandu Valley study area showing different zones in term of Metropolitan City, Municipality and Rural Municipality administrative units 
Geographically, the central lower part of the valley is situated at an elevation of $1425 \mathrm{~m}$ from mean sea level and is surrounded by four mountain ranges namely Shivapuri, Phulchowki, Nagarjun and Chandragiri Hills. KV is one of the most developed city in Nepal with greater portion occupied by the built up area. The mean annual observed air temperature of $\mathrm{KV}$ varied from $16-20^{\circ} \mathrm{C}$ (Karki et al., 2016).

\section{Material and Methods}

\subsection{Materials}

\subsubsection{Landsat-8 Data}

We used Landsat 8 satellite images, OLI (Operational Land Imagery) and TIRS (Thermal Infrared Sensor) 15- to 30- meter multispectral data from Landsat $8 \mathrm{C} 1$ Level-1, for the study which were downloaded from United States Geological Survey (USGS). Thermal band, Band 10, are provided as the atmospheric brightness temperature in Kelvin $(\mathrm{K})$, and the multispectral bands of Landsat-8 OLI is provided as surface reflectance. Band 10 is available at $100 \mathrm{~m}$ horizontal resolution (USGS, 2015, Zanter, 2016). The satellite imageries were selected such that the cloud coverage is less than $10 \%$. Then cloud free images and the satellite images were geo-referenced at Universal Transverse Mercator (UTM) zone 45N projection. We note that the temporal resolution of the data was maintained as much as possible for temporal uniformity over the study period (Table 1). Nevertheless, it was difficult to find the same spatial-resolution data from the available sources due to the cloud cover, which is common in tropical-region Landsat data. However, this matter did not have a considerable effect on findings because the research focused on LST variations over the changed land rather than the absolute value of LST. A comprehensive outline of the necessary metadata and the air-temperature information are outlined in Table 1. Data required were downloaded from Earth Explorer and masked to the area of KV. Then, the LST map for the study area were generated for different time frames from 2013 to 2019 as shown in Table 1. The extracted images for most of the years were obtained for the month of March. So we tend to compare LST for the study area focusing on March and April. The scaling factors $\left(\mathrm{K}_{1}=774.8853\right.$, $\left.\mathrm{K}_{2}=1321.0789, \mathrm{M}_{\mathrm{L}}=0.0003342, \mathrm{~A}_{\mathrm{L}}=0.1\right)$ were used to estimate LST for Band 10 from the metadata file of Landsat imagery where $K_{1}$ and $K_{2}$ are band specific thermal conversion constants, $\mathrm{M}_{\mathrm{L}}$ is multiplicative rescaling factor and $A_{L}$ is additive rescaling factor.

Table 1: Acquisition properties of Landsat satellite images

\begin{tabular}{|c|c|c|c|}
\hline SN & $\begin{array}{c}\text { Acquisition } \\
\text { Year }\end{array}$ & $\begin{array}{c}\text { Acquisition } \\
\text { Date }\end{array}$ & $\begin{array}{c}\text { Cloud } \\
\text { Coverage }(\%)\end{array}$ \\
\hline 1 & 2013 & 26-March & 4.51 \\
2 & 2014 & 26-March & 3.21 \\
3 & 2014 & 11-April & 3.91 \\
4 & 2015 & 01-June & 7.27 \\
5 & 2016 & 15-March & 7.97 \\
6 & 2016 & 18-May & 4.69 \\
7 & 2017 & 02-March & 6.82 \\
8 & 2017 & 03-April & 8.20 \\
9 & 2017 & 05-May & 4.67 \\
10 & 2018 & 22-April & 3.11 \\
11 & 2018 & 08-May & 5.59 \\
12 & 2019 & 24-March & 1.88 \\
\hline
\end{tabular}

\subsection{Methodology}

Methodology adopted by (Kaplan et al., 2018) was used for the analysis purpose. First the different Landsat 8 imageries at different time series (as shown in column 2 and 3 of Table 1) were downloaded. Then, Normalized Difference Vegetation Index (NDVI), proportion of vegetation $\left(\mathrm{P}_{\mathrm{v}}\right)$, and ground emissivity (e) were calculated using Band 4 and 5. Using Band 10 of the image, TOA spectral radiance and radiance were converted to effective temperature $\left(\mathrm{T}_{\mathrm{B}}\right) . \mathrm{T}_{\mathrm{B}}, \mathrm{NDVI}, \mathrm{P}_{\mathrm{v}}$ and emissivity were required to estimate the Land Surface Temperature (LST). The spatial and temporal variation of LST was estimated for the study area (Figure 3). The step wise methodologies to estimate LST is shown in section 3.3.

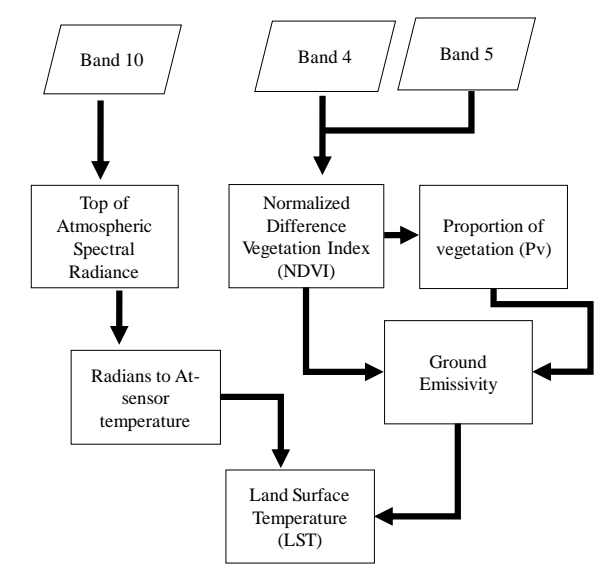

Figure 3: Methodology to estimate Land Surface Temperature (LST) and Normalized Difference Vegetation Index (NDVI) 


\subsection{Step wise methodologies to estimate LST}

Conversion of Spectral Radiance to Top of Atmospheric Brightness Temperature

Landsat 8 satellite imagery obtained is processed in units of radiance using 32-bit floating point calculations. These values were then converted to 16-bit integer values in the finished level 1 product. Conversion to spectral radiance was be done using the radiance scaling factors provided in the metadata file (USGS, 2015) using Equation 1.

$$
L_{\lambda}=M_{\mathrm{L}} * Q_{\mathrm{cal}}+A_{\mathrm{L}}
$$

Thus, calculated spectral radiance is then converted to brightness temperature which is often determined as the effective temperature under unit emissivity. Top of Atmospheric (TOA) Brightness Temperature can be converted from spectral radiance in degree Celsius using Equation 2.

$$
T_{\mathrm{B}}=\frac{K_{2}}{\operatorname{Ln}\left(\frac{K_{2}}{L_{\lambda}}\right)+1}-273.15
$$

Where,

$\mathrm{L}_{\lambda}=$ TOA spectral reflectance (watts $/\left(\mathrm{m}^{2} * \mathrm{sr}^{*} \mu \mathrm{m}\right)$ ) $\mathrm{M}_{\mathrm{L}}=$ Band specific multiplicative rescaling factor $\mathrm{Q}_{\mathrm{cal}}=$ Quantized and calibrated standard product pixel values $(\mathrm{DN})$

$A_{L}=$ Band specific additive rescaling factor

$\mathrm{T}_{\mathrm{B}}=$ effective temperature in degree Celsius

\section{Landsat Surface Temperature Generation}

First, OLI and TIRS band data were converted to radiance using the radiance scaling factors provided in the metadata file using Equation 1 and TOA birghtness temperature using Equation 2. After acquiring TOA brightness temperature, LST for the Landsat 8 using Equation 3-6 was estimated. Parameters such as NDVI, Proportion of vegetation $\left(\mathrm{P}_{\mathrm{v}}\right)$ and ground emissivity (e) were used to estimate the LST. Each parameters NDVI, $\mathrm{P}_{\mathrm{v}}$ and e were calculated using Equation 4, 5 and 6 respectively. NDVI was calculated using Near Infra Red Band $\left(B_{5}\right)$ and Red Band $\left(\mathrm{B}_{4}\right)$ of landsat satellite imagery.

$$
L S T=\frac{T_{\mathrm{B}}}{1+\left(\lambda * \frac{T_{\mathrm{B}}}{C_{2}}\right) * \operatorname{Ln}(e)}
$$

$$
\begin{aligned}
& N D V I=\frac{B_{5}-B_{4}}{B_{5}+B_{4}} \\
& P_{\mathrm{v}}=\left(\frac{N D V I-N D V I_{\min }}{N D V I_{\max }-N D V I_{\min }}\right)^{2} \\
& e=0.004 * P_{\mathrm{v}}+0.986
\end{aligned}
$$

where,

LST $=$ Land Surface Temperature $\left({ }^{\circ} \mathrm{C}\right)$

$\mathrm{T}_{\mathrm{B}}=$ effective temperature in degree Celsius

NDVI $=$ Normalized Difference Vegetation Index calculated using Equation 4

$\mathrm{P}_{\mathrm{v}}=$ Proportion of vegetation calculated using Equation 5

$\mathrm{e}=$ Ground Emissivity calculated from Equation 6

$\lambda$ and $C_{2}$ are constants having values of 10.8 and 14,388 respectively

\section{Results and Discussion}

\subsection{Spatial distribution of LST}

Spatial distribution of LST for the different administrative units (metropolitan city, municipality and rural municipality) is shown in Figure 4 for the temporal time series as illustrated in Table 1. Figure 4 portrays that surface temperature of the metropolitan cities including Kathmandu and Lalitpur (referred as Kathmandu and Lalitpur in Figure 2) has increased to more than $30^{\circ} \mathrm{C}$. The average minimum and maximum LST in the metropolitan administrative units were found to be $21^{\circ} \mathrm{C}$ and $33.3^{\circ} \mathrm{C}$ respectively. The maximum LST was estimated to be $43.1^{\circ} \mathrm{C}$ at Kathmandu metropolitan in 2015. Similarly, the LST at Lalitpur was estimated to be $41.6^{\circ} \mathrm{C}$ which was the highest temperature during the study period in the same year. Heterogeneous distribution of LST was observed in each administrative units of $\mathrm{KV}$ Meanwhile, in the same year LST of the other nearby municipalities of the $\mathrm{KV}$, namely Kirtipur and Madhyapur Thimi were estimated to be 38.8 and $34.7^{\circ} \mathrm{C}$, respectively. Similar to the year 2015 , the high surface temperature was also recorded in year 2018 for the urban administrative units like Kathmandu, Lalitpur and Kirtipur. Most of the time during the research period Kathmandu and Lalitpur 


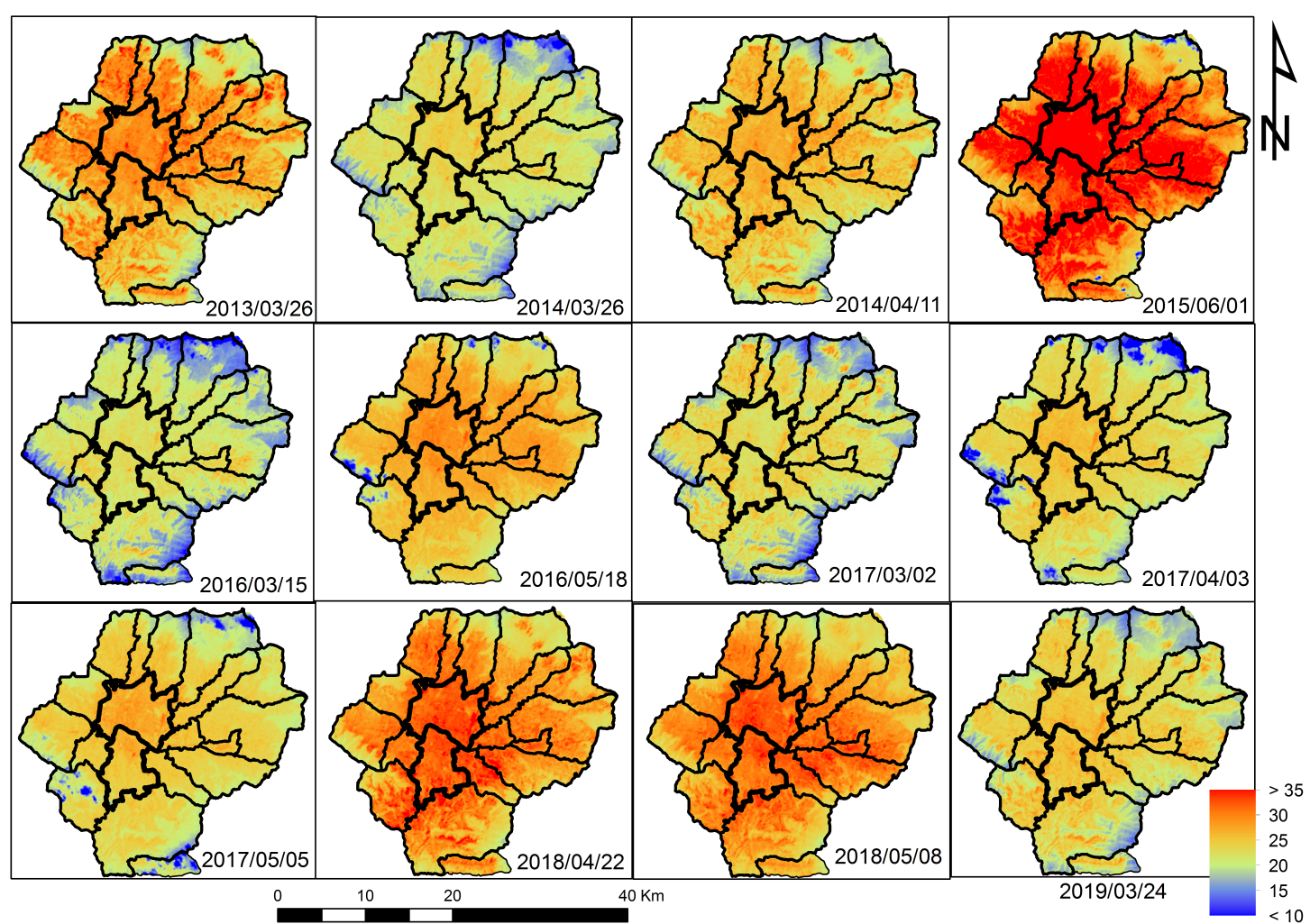

Figure 4: LST (measured in ${ }^{\circ} \mathrm{C}$ ) estimated for Kathmandu Valley study area using Landsat- 8 satellite image

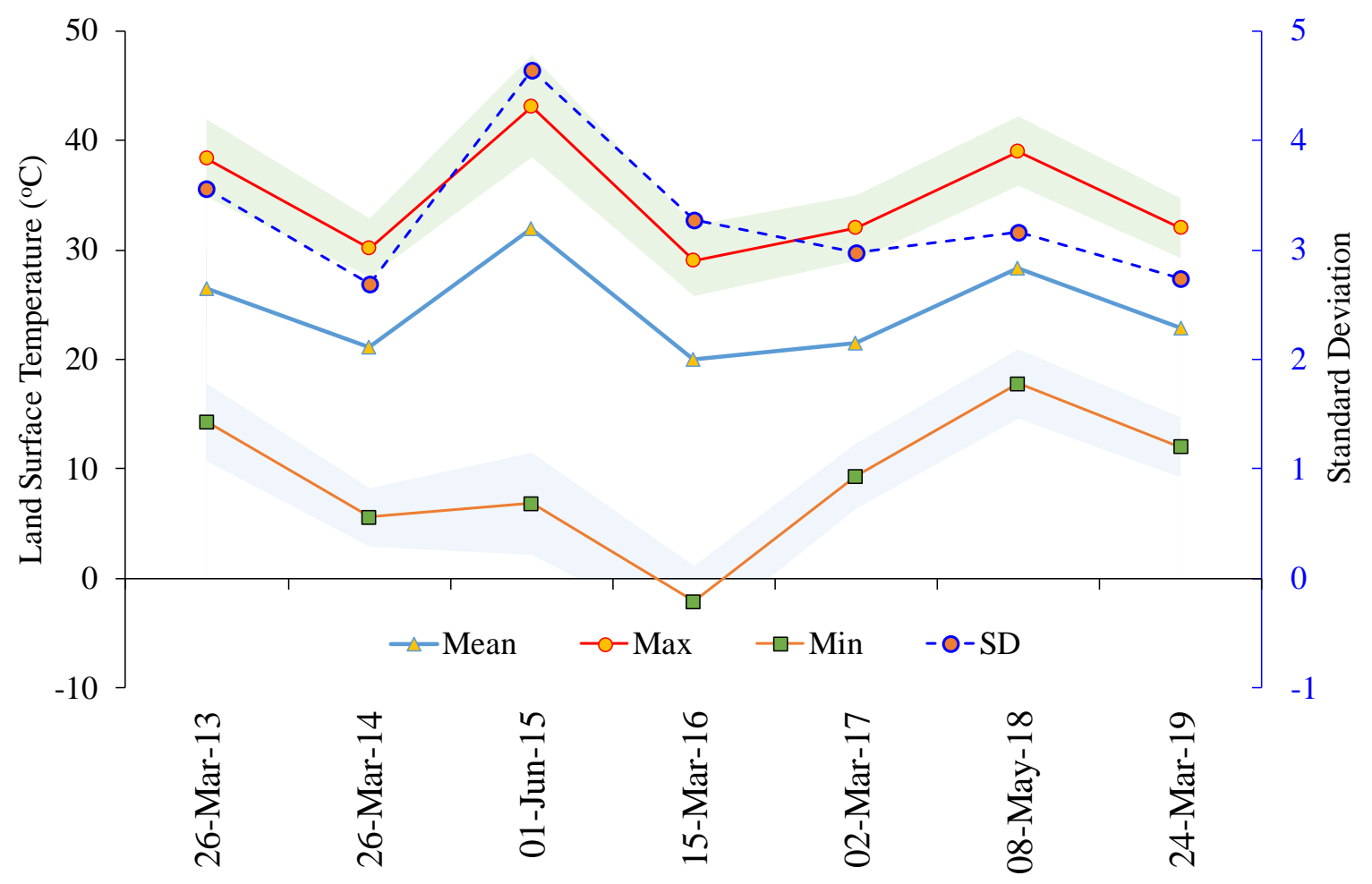

Figure 5: Minimum, mean, maximum, Standard Deviation (SD) of LST measured at study area data acquisition from 2013-2019 
showed higher surface temperature $\left(25^{\circ} \mathrm{C}\right)$ compared to other nearby municipalities (Dakshinkali, Budhalinkatha, Tokha etc). The recordings of high surface temperature might be the result of asphalt covered roadways, concrete rooftop and buildings, as they are highly capable in absorbing the solar radiations Mathew et al. (2016). In addition, increase in the concentration of the dust particles and black carbon content in the aerosol loading might be responsible for increased surface temperature along with the reduced humidity and no rainfall. The increase in population density and land urbanization has further supported in increasing the LST of the urban area within KV. Bottyán and Unger (2003), Liu et al. (2015), Qiao et al. (2020) reported that the increase in the population density and urbanization intensity has substantial effect on LST and UHI of the urban area.

The peri-urban municipalities like Nagarjun, higher altitude region of Budhalinkatha and Godawari had surface temperature ranging from $-2.1^{\circ} \mathrm{C}$ to below $25^{\circ} \mathrm{C}$ most of the research conducted years. The major cities of these peri-urban areas also received the high surface temperature $\left(>25^{\circ} \mathrm{C}\right)$. The mean surface temperature varied from $19.8^{\circ} \mathrm{C}$ to $26.6^{\circ} \mathrm{C}$ in the peri-urban municipalities. The administrative units like Chandragiri, Dakshinkali, Nagarjun, Gokerneshwor, Budhalinkantha and Konjyosom experienced the minimum surface temperature less than $10^{\circ} \mathrm{C}\left(-2.1^{\circ} \mathrm{C}\right.$ in 2016 at Gokarneshwor) which might be the consequence of the high coverage of forest compared to the central KV. The high topographic variation in the peri-urban areas might have resulted in the lesser degree of LST compared to the city centres. The lesser economic and developmental activities also might be the reason for the carbon free aerosols in the air particles of peri-urban areas which resulted in low degree of LST. Temperature of the vegetation canopies reduces the spectral contrast with emissivities equal to unity Salisbury and D'Aria (1992). In contrast, these regions also received the surface temperature more than $40^{\circ} \mathrm{C}$ during June 2015, April and May 2018 . Higher air temperature, reduced humidity (low water content in air) and no rainfall might have contributed to dry up the vegetation cover which resulted in increased surface temperature. Similar results were also reported in Delhi Mallick et al. (2008), Dhaka (Ahmed et al., 2013), Beijing (Yin et al., 2019) and most in the urban centers Peng et al. (2012) of the world.

\subsection{Temporal distribution of LST}

Figure 5 shows the temporal distribution of maximum, minimum, mean, standard deviation (SD) of surface temperature observed for the period of 2013-2019. Figure showed that 01 June 2015 experienced maximum temperature of $43.1^{\circ} \mathrm{C}$ while minimum temperature $\left(-2.12^{\circ} \mathrm{C}\right)$ was observed in 15 March 2016. The study area experienced an average temperature of $23.6^{\circ} \mathrm{C}$ for the temporal period of 2013-2019. The temporal distribution of average LST showed a linear increment of $0.05^{\circ} \mathrm{C}$ during the study period. Our results are analogous with the result shown by Karki et al. (2020). Similarly, the linear regression of maximum and minimum LST shows the increasing rate of $0.02^{\circ} \mathrm{C}$ and $0.39^{\circ} \mathrm{C}$ respectively. The regression results showed that rate of increment of minimum surface temperature was found to be comparatively higher than average and maximum surface temperature. Spatial and temporal values of the average LST for different administrative units is tabulated in Appendix for the entire period. The temporal variation in the surface temperature was found to be heterogeneous in nature. June 2015 was found to receive highest surface temperature followed by April and May in 2018. The monthly distribution of average LST showed the maximum surface temperature of $32^{\circ} \mathrm{C}$ in June and a minimum average LST of $22.3^{\circ} \mathrm{C}$ in March. The average wetness index in the month of March was found to be 0.63 representing the higher coverage of greenness. In the research carried out by Kumari et al. (2018), the temporal distribution of maximum LST increased by 1.5 to $2^{\circ} \mathrm{C}$ during 2003-2007 in Delhi. The annual mean LST showed the positive trend $\left(0.13^{\circ} \mathrm{C}(10\right.$ year) ${ }^{-1}$ ) in the urban Shijiazhuang station in China (Bian et al., 2017). In the time span of 1989-2009 the temporal distribution of LST ranged from 15.4 (1989) to $35.7^{\circ} \mathrm{C}$ (2009) in Dhaka Metropolitan (Ahmed et al., 2013).

\subsection{LST distribution in administrative units}

Heatmap for both maximum and minimum temperature were plotted to observe the spatial and temporal distribution among different administrative units as shown in Figure 6 and Figure 7. Figure 6 showed the higher distribution of maximum temperature for Kathmandu, Lalitpur and Bhaktapur. These administrative units experienced the maximum temperature ranging from $27.3^{\circ} \mathrm{C}$ (March 2014 and 2016) at Bhaktapur to $41.6^{\circ} \mathrm{C}$ (June 2015) at Lalitpur 
metropolitan. The minimum of maximum temperature experienced by the peri-urban area (Tokha) is $24.1^{\circ} \mathrm{C}$ (March 2016) which increased to $28.3^{\circ} \mathrm{C}$ in the same month in 2019. Development activities such as urbanization and increase in the area of barren land might have plunged the peri-urban area in higher degree of surface temperature. Similarly, in June 2015 the surface temperature varied from $36.0^{\circ} \mathrm{C}$ at Konjyosom rural municipality to $43.1{ }^{\circ} \mathrm{C}$ at Kathmandu metropolitan city. The higher degree of LST in Konjyosom might be the result of lesser wetness index (NDVI=0.03). The average surface temperature in $\mathrm{KV}$ was found to be varied from $27.2^{\circ} \mathrm{C}$ at Gokarneshowr municipality to $36.9^{\circ} \mathrm{C}$ at Kathmandu metropolitan city during this month.

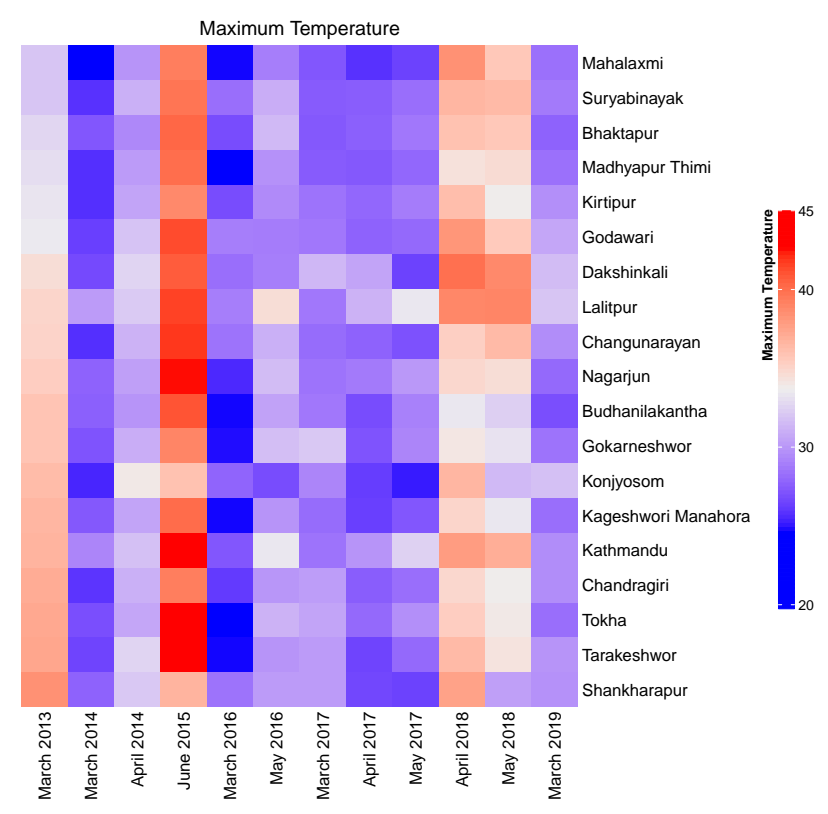

Figure 6: Maximum temperature observed at different administrative unit for the data acquisition period 2013-2019

Figure 7 further showed that the minimum temperature were also higher in Kathmandu, Lalitpur and Bhaktapur administrative units (urban areas) compared to the others (rural areas). Minimum temperature in the urban regions are higher than $17.0^{\circ} \mathrm{C}$ throughout the temporal period of study. The minimum LST was observed at Gokarneshwor municipality $\left(-2.1^{\circ} \mathrm{C}\right)$ in the year 2016. The peri-urban areas received the minimum LST below $13^{\circ} \mathrm{C}$ in the period of 2013-2019. But, the increasing tendency of both the minimum and maximum LST is observed in urban and peri-urban area. This leads to a fact that with the increase in the developmental activities, most of the administrative units in $\mathrm{KV}$ are on the state of rising surface temperature. Further, spatio-temporal variation of the surface temperature revealed that rate of increase of minimum surface temperature is faster than that of maximum surface temperature.

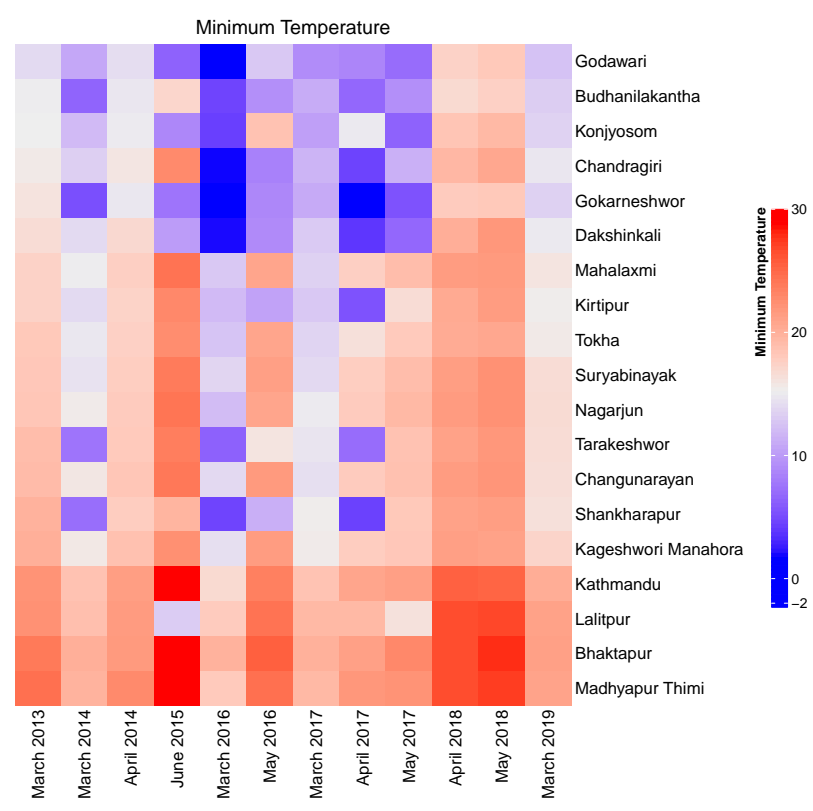

Figure 7: Minimum temperature observed at different administrative unit for the data acquisition period 2013-2019

\section{Conclusions and Recommendation}

Spatial and temporal variation of LST were estimated using Landsat 8 satellite image in different administrative units of $\mathrm{KV}$. The analysis was carried out for the time period of 2013-2019 mainly focusing those periods when the cloud cover is less than $10 \%$. Following are the conclusions drawn from the research.

1. Result of LST shows, Surface temperature is more in the Kathmandu, Bhaktapur, and Lalitpur administrative units compared to nearby municipalities while the regions that are situated at the boundaries of KV experiences LST less than $10^{\circ} \mathrm{C}$. It can be inferred that the zones which are densely populated experiences higher LST.

2. Remotely sensed images can be used for the retrieval of land surface temperature that can be extended to study urban morphology.

3. The temporal distribution of estimated LST 
shows slight increment in LST which might be the impact of urbanization.

4. Satellite images can be employed for managing urban land morphology and evalute the land surface parameter such as UHIs, NDVI, Normalized Difference Built-up Index (NDBI) etc.

5. Apart from the morphology, evaluation of LST would help in managing the temperature related impacts in an urban area.

\section{References}

Ahmed, B., Kamruzzaman, M., Zhu, X., Rahman, M. and Choi, K. (2013). Simulating land cover changes and their impacts on land surface temperature in dhaka, bangladesh, Remote Sensing 5(11): 59695998.

Bian, T., Ren, G. and Yue, Y. (2017). Effect of urbanization on land-surface temperature at an urban climate station in north china, Boundary-layer meteorology 165(3): 553-567.

Bottyán, Z. and Unger, J. (2003). A multiple linear statistical model for estimating the mean maximum urban heat island, Theoretical and applied climatology 75(3-4): 233-243.

Dissanayake, Morimoto, Ranagalage and Murayama (2019). Land-use/land-cover Changes and their impact on surface urban heat islands: case study of Kandy City, Sri Lanka, Climate 7(8): 99.

Donlon, C., Berruti, B., Buongiorno, A., Ferreira, M.H., Féménias, P., Frerick, J., Goryl, P., Klein, U., Laur, H., Mavrocordatos, C. et al. (2012). The global monitoring for environment and security (gmes) sentinel-3 mission, Remote Sensing of Environment 120: 37-57.

Fonseka, H., Zhang, H., Sun, Y., Su, H., Lin, H. and Lin, Y. (2019). Urbanization and its impacts on land surface temperature in colombo metropolitan area, sri lanka, from 1988 to 2016, Remote Sensing 11(8): 957.

Kaplan, G., Avdan, U. and Avdan, Z. Y. (2018). Urban heat island analysis using the landsat 8 satellite data: A case study in skopje, macedonia, Multidisciplinary Digital Publishing Institute Proceedings, Vol. 2, p. 358.
Karki, R., Talchabhadel, R., Aalto, J. and Baidya, S. K. (2016). New climatic classification of nepal, Theoretical and applied climatology 125(3-4): 799808.

Karki, R., ul Hasson, S., Gerlitz, L., Talchabhadel, R., Schickhoff, U., Scholten, T. and Böhner, J. (2020). Rising mean and extreme near-surface air temperature across nepal, International Journal of Climatology 40(4): 2445-2463.

Kumari, B., Tayyab, M., Mallick, J., Khan, M. F., Rahman, A. et al. (2018). Satellite-driven land surface temperature (LST) using Landsat 5, 7 (TM/ETM+ SLC) and Landsat 8 (OLI/TIRS) data and its association with built-up and green cover over urban Delhi, India, Remote Sensing in Earth Systems Sciences 1(3-4): 63-78.

Liu, K., Su, H., Li, X., Wang, W., Yang, L. and Liang, H. (2016). Quantifying spatial-temporal pattern of urban heat island in Beijing: An improved assessment using land surface temperature (LST) time series observations from LANDSAT, MODIS, and Chinese new satellite GaoFen-1, IEEE Journal of Selected Topics in Applied Earth Observations and Remote Sensing 9(5): 2028-2042.

Liu, Y., Yuan, Z., Kong, W., Sun, B. and Bin, A. (2015). The changing trend of heat island intensity and main influencing factors during 1993-2012 in xi' an city, J. Nat. Resour 30: 974-985.

Mallick, J., Kant, Y. and Bharath, B. (2008). Estimation of land surface temperature over Delhi using Landsat-7 ETM+, J. Ind. Geophys. Union 12(3): 131-140.

Mathew, A., Khandelwal, S. and Kaul, N. (2016). Spatial and temporal variations of urban heat island effect and the effect of percentage impervious surface area and elevation on land surface temperature: Study of chandigarh city, india, Sustainable Cities and Society 26: 264-277.

Meng, Q., Zhang, L., Sun, Z., Meng, F., Wang, L. and Sun, Y. (2018). Characterizing spatial and temporal trends of surface urban heat island effect in an urban main built-up area: A 12-year case study in beijing, china, Remote Sensing of Environment 204: 826837.

Peng, S., Piao, S., Ciais, P., Friedlingstein, P., Ottle, C., Breéon, F.-M., Nan, H., Zhou, L. and Myneni, R. B. 
(2012). Surface urban heat island across 419 global big cities, Environmental science \& technology 46(2): 696-703.

Qiao, Z., Liu, L., Qin, Y., Xu, X., Wang, B. and Liu, Z. (2020). The impact of urban renewal on land surface temperature changes: a case study in the main city of guangzhou, china, Remote Sensing 12(5): 794.

Ravanelli, R., Nascetti, A., Cirigliano, R. V., Di Rico, C., Leuzzi, G., Monti, P. and Crespi, M. (2018). Monitoring the impact of land cover change on surface urban heat island through Google Earth Engine: Proposal of a global methodology, first applications and problems, Remote Sensing 10(9): 121.

Salisbury, J. W. and D'Aria, D. M. (1992). Emissivity of terrestrial materials in the 8-14 $\mu \mathrm{m}$ atmospheric window, Remote sensing of Environment 42(2): 83106.

Shakya, B. M., Nakamura, T., Shrestha, S. D. and Nishida, K. (2019). Identifying the deep groundwater recharge processes in an intermountain basin using the hydrogeochemical and water isotope characteristics, Hydrology Research 50(5): 12161229.

Thapa, B. R., Ishidaira, H., Pandey, V. P. and Shakya, N. M. (2017). A multi-model approach for analyzing water balance dynamics in kathmandu valley, nepal, Journal of Hydrology: Regional Studies 9: 149-162.

USGS (2015). Landsat 8 (18) data users handbook, USGS 1.

Yamamoto, Y., Ishikawa, H., Oku, Y. and Hu, Z. (2018). An algorithm for land surface temperature retrieval using three thermal infrared bands of himawari-8, Journal of the Meteorological Society of Japan. Ser. II .

Yang, S. and Wang, S. (1989). The effect of the afforestation trees in lowering temperatures and enhancing humidity of the air in guangzhou. geographical series iii, Journal of South China Normal University pp. 41-46.

Yin, J., Wu, X., Shen, M., Zhang, X., Zhu, C., Xiang, H., Shi, C., Guo, Z. and Li, C. (2019). Impact of urban greenspace spatial pattern on land surface temperature: a case study in beijing metropolitan area, china, Landscape Ecology 34(12): 2949-2961.

Yuan, F. and Bauer, M. E. (2007). Comparison of impervious surface area and normalized difference vegetation index as indicators of surface urban heat island effects in landsat imagery, Remote Sensing of environment 106(3): 375-386.

Zanter, K. (2016). Landsat 8 (18) data users handbook, Landsat Science Official Website . 


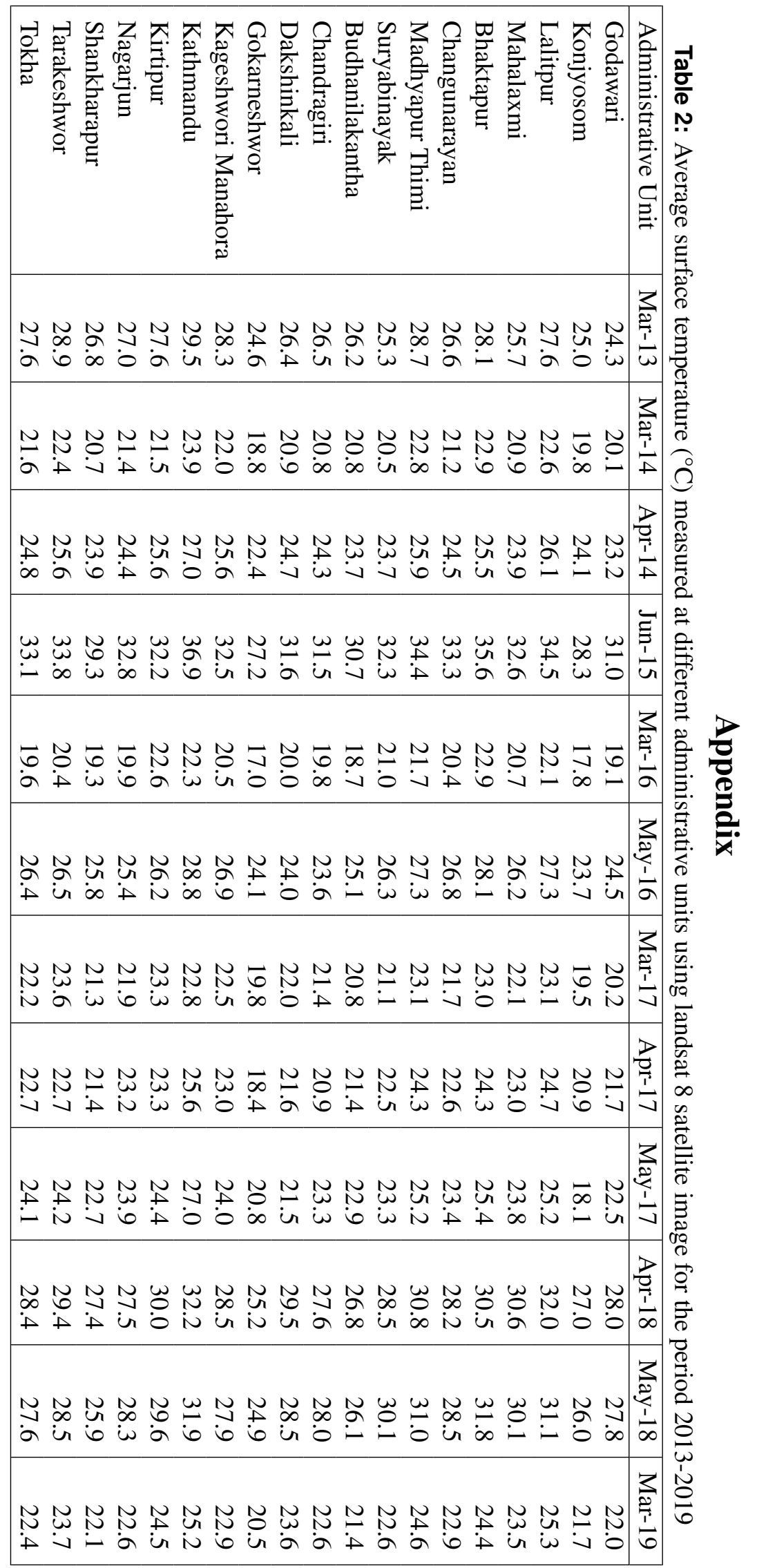

